\title{
Use of Worksheets to Develop the Skill of Using Geometrical Instruments
}

\author{
Sharmila L Mascarenhas
}

Assistant Professor, St Ann's College of Education, Autonomous, Mangaluru, Karnataka, India

Corresponding author: mayfair23@yahoo.in

Received: $28-02-2020$

Revised: 22-06-2020

Accepted: 26-07-2020

\begin{abstract}
Geometry, a branch of Mathematics develops the reasoning and logical thinking power of the child. Nearly every curriculum advisory body gives strong support to the inclusion of informal Geometry in early instruction. But the picture of Geometry is imprecise in relation to learning. In order to fulfil the objectives of Teaching of Geometry, it must be given utmost importance and this can be achieved by developing the Skill of using Geometrical Instruments in an appropriate manner in the learners. The present study titled 'Use of Worksheets on developing the Skill of Using Geometrical Instruments' is an experimental study. The population of the study constituted all the students of the Standard Eight of Mangaluru Taluk. Randomly selected sixty students were the sample of the study. An Instructional material consisting of worksheets and lesson plans on the use of commonly used Geometrical Instruments by the students of Standard Eight was prepared by the investigator and was validated. An Achievement test and an Observation Schedule was constructed and validated to measure the Skill of using Geometrical Instruments. The data was analyzed using descriptive statistics namely, mean, median and Standard Deviation. Inferential statistics ' $t$ ' test was used to test the significance of the difference between the means of scores. Hypotheses were tested at 0.05 level of significance. The study revealed that there is a significant effect of Use of Worksheets on developing the Skill of Using Geometrical Instruments.
\end{abstract}

Keywords: Mathematics Education, Use of Worksheets, Skill of Using Geometrical Instruments, High, Average and Low Achievers

The present study titled 'Use of Worksheets on developing the Skill of Using Geometrical Instruments' is an experimental study. Mathematics is intimately involved in every moment of everyone's life. In this world of today, nobody can live without Mathematics for a single day. Mathematics is a core subject in our educational system both at the primary and secondary level. In the 1960s, Mathematics Education in almost all countries developed qualitatively by including the teaching of modern mathematics in school education. This development become necessary to prepare today's children to face the challenges of the future electronic age.

Geometry, a branch of Mathematics which is the science of space and extent deals with the position, space and size of the bodies but has nothing to do with their material or physical properties. From time immemorial humans have found that the concepts of size, shape and position are ever prominent in the pattern of his environment and that the Geometric principles of equality, symmetry, congruency and similarity needs to measure objects of various kinds such as floor, field and boxes. That evidently indicates the indispensable call for informal Geometry. Geometry develops the reasoning and logical thinking power of the child. It improves the

How to cite this article: Mascarenhas, S.L. (2020). Use of Worksheets to Develop the Skill of Using Geometrical Instruments. Educational Quest: An Int. J. Edu. Appl. Soc. Sci., 11(2): 87-91.

Source of Support: None; Conflict of Interest: None (c) 9 
aesthetic sense of the child with respect to different shapes, sizes and structures of things. It provides an opportunity for creative thinking in the child. Further, vocational competence can be developed in the child to be efficient in painting, designing, drawing maps, engineering etc.

Geometry has been a core subject in Mathematical education at least since the entry to Plato's Academy bore the inscription "Let No One Be Ignorant of Geometry Enter Here". Traditional school Mathematics curricula have treated Geometry on three bases:

$\square$ First experience in Geometry at Elementary and Secondary levels, contemplate on informal study of basic shapes and their properties. Measurement of length, area, and volume is applied to a variety of practical problems.

$\square$ At some stage of Higher Secondary Education maximum students study the organization of Geometric ideas and facts in a formal axiomatic system.

$\square$ In the later years calculus is learnt by a handful of students who encounter vector and analytic Geometry.

Nearly every curriculum advisory body gives strong support to the inclusion of informal Geometry in early instruction. But the picture of Geometry is imprecise in relation to learning. Consequently, Geometry is not the choice of many students. Majority of students are anxious of Geometry and have developed a phobia for it. The lack of interest in geometry is mounting day after day. In fact, Geometry is taught like a mechanical subject without thinking, creativity and imagination. Hence, there is a need to create interest in Geometry among the students and then only the objectives of teaching Mathematics in the context of Geometry can be achieved. These objectives of teaching Geometry are:

To develops the ability to use Geometrical Instruments and tools skillfully.

To develop essential Skills in surveying or measuring processes.

To develop essential skills in drawing, reading and interpretation of graphs.

In order to accomplish these objectives, teaching of Geometry must be given utmost importance and this can be achieved by developing the Skill of using
Geometrical Instruments in an appropriate manner in the learners.

Mathematics was to be studied as a core subject in the context of Universalization of Elementary Education. The Kothari Commission on National Education (1964) recommended that every student should study Mathematics for ten years emphasizing the comprehension of basic principles. The National Policy Education (1986) also reiterated the importance of the teaching Mathematics in school education, suggesting the development of thinking, reasoning and logical analysis in the learner. The program of action to implement the National Policy organized the fact that, the quality of teaching Mathematics in our schools has not been satisfactory. The National Curriculum Framework for School Education, 2000 focused on the quantification of experiences with numbers and forms of Geometry. The NCF 2005 recommended that high quality Mathematics education should be offered to children.

\section{Significance and Rationale of the study}

Most of the time, we measure the learning outcomes only by looking at the end product in an exam, but the process is also as important as the end product. So it is the duty of a Mathematics Teacher to teach Geometry to make sure that all students attain the Skills of using Geometrical Instruments and so the investigator attempted to find the effectiveness of the Use of Worksheets on developing the Skill of Using Geometrical Instruments.

The function of the workbook consisting of number of worksheets in Mathematics is more specialized. Workbooks are merely specialized and elaborated forms of a teaching device that has been in use as long as Mathematics has been taught from books namely, the suggestion of problem and activities through which it is expected that students will acquire the desirable skills, understanding abilities and appreciations.

Kundu Souman Chandra (2018) in the study on Attitude of Secondary Level Students towards Geometry revealed that residential place is significant in developing attitude towards geometry whereas gender plays no significant role. Keith Jones and Marianna Tzekaki (2016) conducted a study on the Teaching and Learning of Geometry emphasised geometry education in the form of Spatial Reasoning, 
geometric visualization, geometric reasoning and the design and use of geometric tasks. Bhagat Kaushal Kumar and Chang Chun Yen (2015) in their study on Incorporating Geogebra into Geometry Learning - A lesson from India proved that Geogebra is an effective tool for Teaching and Learning of Geometry. Mamatha Suvarna (2011) conducted a study on Effectiveness of the use of Worksheets in developing the Skill of using geometrical instruments among Eight Standard students and found that use of work sheets was effective in developing Skill of using geometrical instruments. Kothari R.G. and Patel Rachana N. (2009) made a study on the Diagnosis and Remediation of Learning Difficulties in Geometry of Standard Eight Students and proved that remedial measures helped students to reduce the learning difficulties through the use of interactive method and teaching materials. Chandrashekar (2007) conducted a study on teaching of Geometry at secondary school level aimed at assessing the state of teaching Geometry in schools, the investigator concluded that the teaching and learning of Geometry in secondary schools is poor and attributes this to examination systems.

The review of literature has given an insight to the researcher to study to conduct research in the area of Use of worksheets to develop the skill of using Geometrical instruments.

\section{Statement of the Problem}

Effect of the Use of Worksheets to develop the Skill of Using Geometrical Instruments among the Students of Standard Eight of Mangalore Taluk.

\section{Operational Definitions of the Terms}

1. Use of Worksheets: The worksheet refers to a sheet of paper on which work records are kept. In the present study it refers to the classroom use of the Worksheets designed by the investigator to enable the pupils to master a specific Skill on which constructions are made and computations are set down.

2. Geometrical Instruments: The instruments used in the Geometry class, namely pencil, foot ruler, compass, divider, protractor and setsquares. In the present study the Geometrical Instruments include Pencil, Foot ruler, Compass, Dividers, protractors and setsquares.
* Pencil: Instrument for writing or drawing.

* Foot Ruler: Straight strip of wood, metal, or plastic used to draw or measure.

* Compass: An instrument for taking measurements and describing circles with two straight arms connected at one end by a movable joint.

* Divider: A form of compass, sometimes with a screw for setting to small intervals.

* Protractor: An instrument for measuring angles usually in the form of a graduate semi-circle.

* Set square: Right angled triangular plate for determining, measuring or setting out set angles.

3. Skill of using Geometrical Instruments: It refers to the proficiency of the students in making the appropriate use of Geometrical Instruments in the learning of Geometry.

4. Students of Standard Eight: Students studying in Standard Eight of Mangaluru Taluk of Dakshina Kannada district following the state syllabus of Karnataka state.

5. Mangalore Taluk: One of the Taluks of Dakshina Kannada District of Karnataka State.

6. High and Average Achievers: The Mathematics scores of the semester end exams are used to categorise the students as high and average achievers.

\section{Objectives of the Study}

To find the effect of the Use of Worksheets and non use of Worksheets on the Skill of using Geometrical Instruments among the students of Standard Eight of Mangaluru Taluk.

$\square$ To find the effect of the Use of Worksheets and non use of Worksheets on the Skill of using Geometrical Instruments among the Average Achievers of Standard Eight of Mangaluru Taluk.

To find the effect of the Use of Worksheets and non use of Worksheets on the Skill of using Geometrical Instruments among the Low Achievers of Standard Eight of Mangaluru Taluk. 


\section{Hypotheses of the Study}

$\mathbf{H}_{\mathbf{0}} \mathbf{1}$ : There is no significant difference on the effect of the Use of Worksheets and non use of Worksheets on the Skill of using Geometrical Instruments among the students of Standard Eight of Mangaluru Taluk.

$\mathbf{H}_{\mathbf{0}}$ 2: There is no significant difference on the Use of Worksheets and non use of Worksheets on the Skill of using Geometrical Instruments among the Average Achievers of Standard Eight of Mangaluru Taluk.

$\mathbf{H}_{0} 3$ : There is no significant difference on the Use of Worksheets and non use of Worksheets on the Skill of using Geometrical Instruments among the Low Achievers of Standard Eight of Mangaluru Taluk.

\section{Methodology}

The present study was experimental in nature with post test two group design. The population of the study constituted all the students of the Standard Eight of Mangaluru Taluk. Randomly selected sixty students were the sample of the study. An Instructional material consisting of worksheets and lesson plans on the use of commonly used Geometrical Instruments by the students of Standard Eight was prepared by the investigator and was validated. An Achievement test and an Observation Schedule was constructed and validated to measure the Skill of using Geometrical Instruments. The data was analyzed using descriptive statistics namely, mean, median and Standard Deviation. Inferential statistics ' $t$ ' test was used to test the significance of the difference between the means of scores. Hypotheses' were tested at 0.05 level of significance.

\section{Analysis and Interpretation of Data}

Objective One: To find the effect of the Use of Worksheets and non use of Worksheets on the Skill of using Geometrical Instruments among the students of Standard Eight of Mangaluru Taluk.

Table 1: Details of the Scores on Use of Worksheets and non use of Worksheets on the Skill of using Geometrical Instruments among the students of Standard Eight of Mangaluru Taluk

\begin{tabular}{llllll}
\hline Variables & N & Mean S.D & t & Remarks \\
\hline $\begin{array}{l}\text { Non use of worksheet } \\
\text { Control Group }\end{array}$ & 30 & 37.33 & 10.88 & \\
\hline $\begin{array}{l}\text { Use of Worksheets } \\
\text { Experimental Group }\end{array}$ & 30 & 63.8 & 13.31 & $\begin{array}{l}\text { Significant } \\
0.05 \text { level }\end{array}$ \\
\hline
\end{tabular}

From the table 1, it is observed that the mean scores obtained from the Achievement Test scores of the Experimental group is higher than that of the control group. It is observed that the calculated " $\mathrm{t}$ " value 11.9 is greater than the theoretical value of 1.98 at 0.05 Level. Hence the null hypothesis was rejected and the research hypothesis 'There is a significant difference on the effect of the Use of Worksheets and non use of Worksheets on the Skill of using Geometrical Instruments among the students of Standard Eight of Mangaluru Taluk' was accepted. Hence it can be concluded that Use of Worksheets is significantly more effective in developing the Skill of Using Geometrical Instruments among the students of Standard Eight of Mangaluru Taluk.

Objective Two: To find the effect of the Use of Worksheets and Non use of Worksheets on the Skill of using Geometrical Instruments among the High Achievers of Standard Eight of Mangaluru Taluk.

Table 2: Details of the Scores on Use of Worksheets and non use of Worksheets on the Skill of using Geometrical Instruments among the Average Achievers of Standard Eight of Mangaluru Taluk

\begin{tabular}{llllll}
\hline Variables & N & Mean & S.D & t & Remarks \\
\hline $\begin{array}{l}\text { Non use of worksheet } \\
\begin{array}{l}\text { Control Group } \\
\text { Use of Worksheets }\end{array}\end{array}$ & 42.5 & 9 & & \\
$\begin{array}{l}\text { Uxperimental Group } \\
\begin{array}{l}\text { Experimen } \\
\text { 15 }\end{array}\end{array}$ & 72 & 10.62 & $\begin{array}{l}\text { Significant } \\
\text { at } 0.05 \text { level }\end{array}$ \\
\hline
\end{tabular}

From the Table 2, it is observed that the calculated ' $\mathrm{t}$ ' value 17.98 is greater than the theoretical value of 2.02 at 0.05 Level. Hence the null hypothesis was rejected and the research hypothesis 'There is a significant difference on the Use of Worksheets and non use of Worksheets on the Skill of using Geometrical Instruments among the Average Achievers of Standard Eight of Mangaluru Taluk was accepted.

From the Table 2, it is also observed that the Mean scores of Experimental group is higher than the control group. Hence it can be concluded that Use of Worksheet is significantly more effective in developing the Skill of Using Geometrical Instruments in case of Average Achievers.

Objective Three: To find the effect of the Use of Worksheets and non use of Worksheets on the Skill of using Geometrical Instruments among the Low Achievers of Standard Eight of Mangaluru Taluk. 
Table 3: Details of the Scores on Use of Worksheets and non use of Worksheets on the Skill of using Geometrical Instruments among the Low Achievers of Standard Eight of Mangaluru Taluk

\begin{tabular}{|c|c|c|c|c|c|}
\hline Variables & $\mathbf{N}$ & Mean & S.D & $t$ & Remarks \\
\hline $\begin{array}{l}\text { Non use of worksheet } \\
\text { Control Group }\end{array}$ & 15 & 30.5 & 9.22 & & \multirow{2}{*}{$\begin{array}{l}\text { Significant at } \\
0.05 \text { level }\end{array}$} \\
\hline $\begin{array}{l}\text { Use of Worksheets } \\
\text { Experimental Group }\end{array}$ & 15 & 54 & 8.53 & 14.16 & \\
\hline
\end{tabular}

From the Table 3, it is observed that the calculated ' $t$ ' value 14.16 is greater than the theoretical value of 2.02 at 0.05 Level. Hence the null hypothesis was rejected and the research hypothesis 'There is no significant difference on the Use of Worksheets and non use of Worksheets on the Skill of using Geometrical Instruments among the Low Achievers of Standard Eight of Mangaluru Taluk' was accepted. Hence it can be concluded that Use of Worksheets are significantly more effective in developing the Skill of Using Geometrical Instruments in case of Low Achievers.

\section{Major Findings of the Study}

Use of Worksheets is significantly more effective in developing the Skill of Using Geometrical Instruments among the students of Standard Eight of Mangaluru Taluk.

$\square$ Use of Worksheet is significantly more effective in developing the Skill of Using Geometrical Instruments in case of Average Achievers among the students of Standard Eight of Mangaluru Taluk.

$\square$ Use of Worksheets are significantly more effective in developing the Skill of Using Geometrical Instruments in case of Low Achievers among the students of Standard Eight of Mangaluru Taluk.

\section{Implications of the Study}

Innovative worksheets for learners to teach Mathematics in general and Geometry in particular make the foundational concepts simple and interesting.
Teachers can make use of worksheets to assist the average and the low achievers in the classroom, so that comprehension and retention is better.

$\square$ Use of Geometrical instruments through guided instruction can facilitate the learners make the right and appropriate use of, thus make learning of Geometry interesting.

$\square$ Less motivated students could be helped to learned better through the use of worksheets and hence positively influence their achievement in Mathematics.

$\square$ Learners could be skilled in the accurate use of Geometrical instruments to prevent errors in Geometry.

\section{REFERENCES}

Bhagat, Kaushal, Kumar and Chang, Chun, Yen. 2015. Incorporating Geogebra into Geometry Learning - A lesson from India. Eurasia Journal of Mathematics, Science and Technology Education, 11(1): 77-86.

Chandra, Kundu, Soumen. 2018. Attitude of Secondary Level Students towards Geometry. International Journal of Research and Analytical review, 5(3).

Chandrashekar, C. 2007. Teaching of Geometry at Secondary Level. Edutraks, 6(10).

Keith, Jones and Marianna, Tzekaki. 2016. Teaching and Learning of Geometry. The Second Handbook of Research on the Psychology of Mathematics Education, pp. 109149. Retrieved from https://www.researchgate.net/ publication/305635480_Research_on_the_teaching_and_ learning_of_geometry on 27-08-2020

Kothari, R.G. and Patel, Rachana, N. (2009). Diagnosis and Remediation of Learning Difficulties in Geometry of Standard Eight Students. Thesis submitted to The Maharaja Sayajirao University of Baroda. Retrieved from http://hdl. handle.net/10603/58606 on 28-08-2020

Suvarna, Mamata. 2011. Effectiveness of the Use of Worksheets on developing the Skill of using Geometrical Instruments among the Students of Standard Eight of Mangaluru Taluk. Unpublished Dissertation submitted to Mangalore University. 
